\title{
Effect of ultrasonic field treatment on degassing of 2024 alloy
}

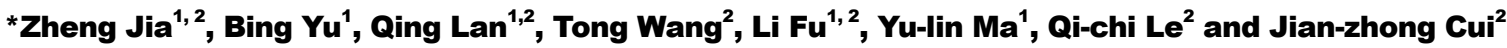 \\ 1. College of Mechanical Engineering, Shenyang University, Shenyang 110044, China \\ 2. Key Laboratory of Electromagnetic Processing of Materials, Ministry of Education, Northeastern University, Shenyang 110819, China
}

\begin{abstract}
The 2024 aluminum alloy was prepared with different ultrasonic processes. Effects of ultrasonic treatment parameters including ultrasonic power, treatment time, treatment temperature, and frequency resonance, as well as $\mathrm{C}_{2} \mathrm{Cl}_{6}$ degasser on degassing of the 2024 aluminum alloy were investigated. Results indicate that increasing ultrasonic power at the same ultrasonic treatment time can improve the degassing effect. The optimum degassing efficiency can be obtained under the resonant ultrasound condition. With the combination of $1 \% \mathrm{C}_{2} \mathrm{Cl}_{6}$ addition and $150 \mathrm{~W}$ ultrasonic treatment for $40 \mathrm{~s}$, the hydrogen content of the alloy is decreased by $52.9 \%$. At the same time, the tensile strength and elongation are increased by $28.3 \%$ and $92.3 \%$, respectively, and the yield strength is slightly increased by $6.7 \%$. The degassing mechanism is also discussed.
\end{abstract}

Key words: ultrasonic degassing; $\mathrm{C}_{2} \mathrm{Cl}_{6}$ degasser; hydrogen content; tensile properties

CLC numbers: TG146.21 Document code: A Article ID: 1672-6421(2021)02-124-07

\section{Introduction}

It is well known that high-energy ultrasound has a unique acoustic effect on aluminum alloys during solidification. The coarse columnar grains become fine equiaxed ones, and the macro- and micro-segregation are also alleviated obviously when ultrasonic vibration is applied on the solidification process ${ }^{[1-7]}$. However, porosities still can be found in the ingots, which are extremely detrimental to the mechanical properties, fatigue resistance and corrosion resistance of aluminum alloys. Therefore, to prevent and eliminate the formation of porosities during the solidification process under ultrasonic vibration treatment is of great importance.

Currently, the ultrasonic degassing method has attracted much attention due to its environmental friendliness and resource economy. Some researchers found that the mechanism of ultrasonic degassing was intimately attributed to cavitation, which depends on ultrasonic power ${ }^{[8,9]}$. Increasing ultrasonic power could improve the degassing effect. Recently, it was reported by Oak Ridge National Laboratory that the ultrasonic degassing efficiency of A356 alloy melt was related

\section{*Zheng Jia}

Male, born in 1982, Ph. D. His research interest mainly focuses on light alloy forming technology.

E-mail: jz140@163.com;

Received: 2020-06-28; Accepted: 2020-12-10 to the ultrasonic treating temperature or time ${ }^{[10,11]}$. The results indicated increasing either temperature or treating time could improve the degassing effect. $\mathrm{Wu}$ and Lü, et al. ${ }^{[12-15]}$ considered that the degassing effect in the melt or semi-solid slurry aluminum alloys was a combined action of cavitation and ultrasound acoustic streaming, which was related to ultrasonic power. The effectiveness of ultrasonic degassing is affected by many factors, including power, ultrasonic duration, treating temperature, resonance or non-resonance and so on ${ }^{[16]}$. Therefore, to obtain the optimized ultrasonic degassing parameters of industrial aluminum alloy is of significance.

The 2024 alloy is a heat-resistant aluminum alloy which has excellent mechanical properties, but this alloy easily produces pores during the melting process. In this study, 2024 alloy was prepared under ultrasonic degassing. The parameters, including ultrasonic treating temperature, treating time, ultrasonic power frequency of resonance and non-resonance, and addition of $\mathrm{C}_{2} \mathrm{Cl}_{6}$ degasser on degassing, were studied to find the optimum ones. The mechanical properties of the ingot after ultrasonic degassing treatment with optimized parameters were also studied, and the ultrasonic degassing mechanism was discussed in detail.

\section{Experimental procedure}

The experimental set-up is shown in Fig. 1. It consists 
of an ultrasonic generator (power: 0-150 W; frequency: $20 \pm 2 \mathrm{kHz}$ ), piezoelectric transducer, ultrasonic radiator, wind cooling system, and temperature control system. During the ultrasonic treatment (UST), the temperature of the melt, the preheating temperature of the radiator and the duration of treatment were precisely measured and controlled.

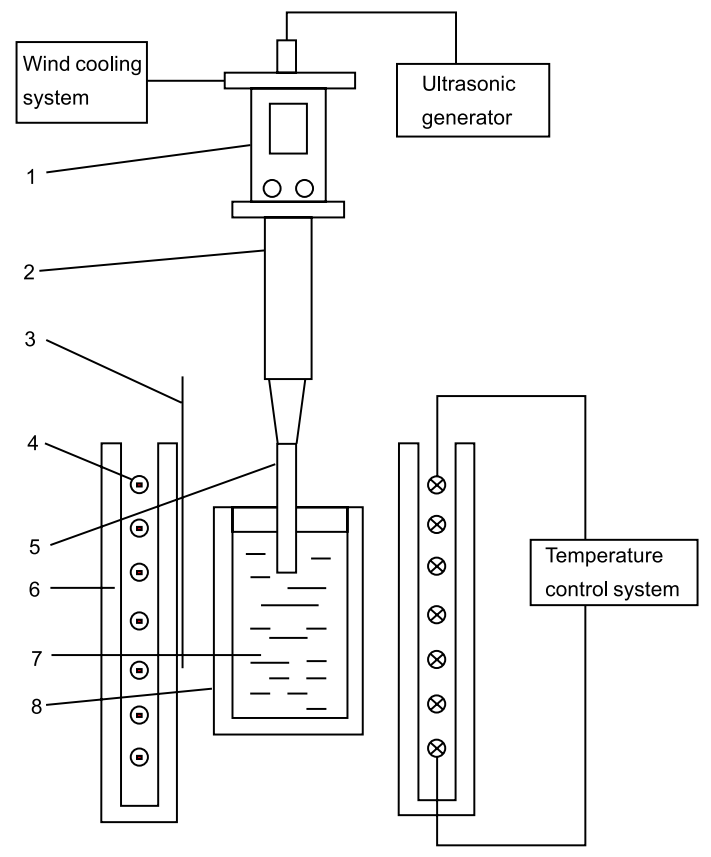

1 - Ultrasonic transducer; 2 - Cone; 3 - Thermocouple

4 - Resistance heater; 5 - Ultrasonic radiator; 6 - Ceramic tube;

7 - 2024 alloy melt; 8 - Graphite crucible

Fig. 1: Schematic diagram of ultrasonic treatment experimental set-up

A graphite crucible containing about $4.5 \mathrm{~kg} 2024$ aluminum alloy was melted at $1,033 \mathrm{~K}$ in an electric resistance furnace, and held for $10 \mathrm{~min}$. Then, the liquid metal was poured into a graphite crucible preheated to $1,003 \mathrm{~K}$ with a capacity of $1.1 \mathrm{~kg}$. The preheated ultrasonic radiator was inserted into the melt about $10 \mathrm{~mm}$ below the liquid surface for $10 \mathrm{~min}$ when the ultrasonic treatment temperature reached the preset value of 953,983 and 1,003 K. After that, the hydrogen content was measured using an Alscan hydrogen analyzer. Finally, the melt was poured into a water-cooled copper mold $(200 \mathrm{~mm} \times$ $100 \mathrm{~mm} \times 10 \mathrm{~mm}$ ) at $993 \mathrm{~K}$. The measured composition of the experimental alloy was shown in Table 1 , and the detailed experimental parameters were shown in Table 2. The tensile samples were machined from the cylindrical ingots along the longitudinal direction. The microstructure and porosities in the center of the specimens were observed by optical microscopy (OM, Leica DMR).

Table 1: Chemical composition of 2024 aluminum alloy (mass\%)

\begin{tabular}{cccccccc} 
Cu & Mg & Mn & Zn & Cr & Si & Fe & Al \\
\hline 4.35 & 1.37 & 0.637 & 0.017 & 0.053 & 0.088 & 0.098 & Bal.
\end{tabular}

Table 2: Experimental parameters

\begin{tabular}{cc} 
Parameters & Values \\
\hline Ultrasonic power $(\mathrm{W})$ & $0,45,75,120,150$ \\
Ultrasonic frequency $(\mathrm{kHz})$ & $20 \pm 2$ \\
Ultrasonic treatment temperature (K) & $953,983,1003$ \\
Ultrasonic treatment time (s) & $0,20,40,60,80,100$ \\
Insertion depth of radiator $(\mathrm{m})$ & 0.01
\end{tabular}

\section{Results and discussion}

\subsection{Effect of ultrasonic treatment power on degassing efficiency}

Figure 2 shows the degassing efficiency of 2024 alloy as a function of ultrasonic treating time with different ultrasonic powers (degassing at 1,003 K). The hydrogen content of untreated alloy is $0.174 \mathrm{~mL} / 100 \mathrm{~g}$. It can be seen that at the same treatment time, the degassing efficiency can be enhanced by increasing ultrasonic power. When the ultrasonic power is $45 \mathrm{~W}$, the degassing efficiency reaches a maximum of $31.7 \%$ at $100 \mathrm{~s}$. It takes only $80 \mathrm{~s}$ for the degassing efficiency to achieve the maximum of $52.5 \%$ when the ultrasonic power is $150 \mathrm{~W}$.

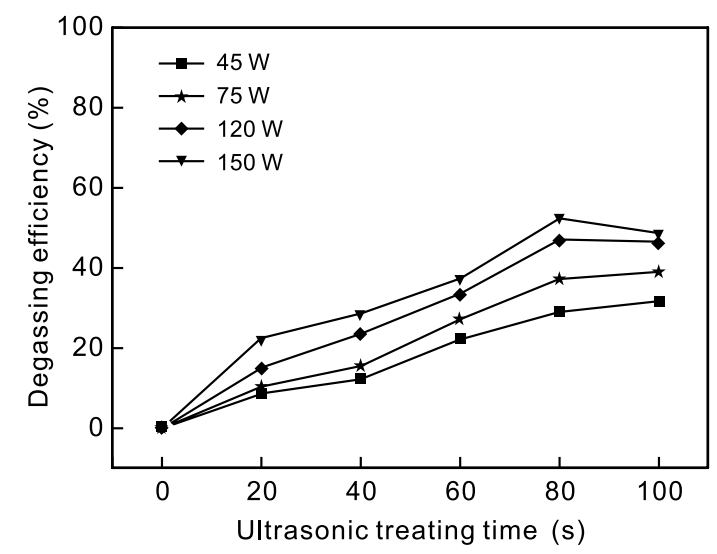

Fig. 2: Relationship between degassing efficiency and treating time with different ultrasonic power levels

It is considered that the degassing efficiency is intimately related to acoustic pressure value and the cavitation in the melt, which can be expressed by the following equation ${ }^{[17]}$ :

$$
P_{\mathrm{k}}=\sqrt{\frac{2 P \rho_{\mathrm{L}} c_{\mathrm{L}}}{S}}
$$

where $P_{\mathrm{k}}$ is the acoustic pressure $(\mathrm{Pa}), P$ is the ultrasonic power $(\mathrm{W}), \rho_{\mathrm{L}}$ is the density of 2024 aluminum melt $\left(\mathrm{kg} \cdot \mathrm{m}^{-3}\right), c_{\mathrm{L}}$ is the speed of ultrasound in aluminum alloy melt $\left(\mathrm{m} \cdot \mathrm{s}^{-1}\right)$ and $S$ is the area of ultrasonic radiator end $\left(\mathrm{m}^{2}\right)$.

The acoustic pressure $\left(P_{\mathrm{k}}\right)$ in the melt increases with an increase in ultrasonic power $(P)$. When the acoustic pressure in the melt is low, a few cavitation bubbles nucleate and grow up, and formation time is very long. Then little gas (the main 
content is hydrogen) can dissolve in the melt and diffuse towards the cavitation bubbles. It finally leads to a poor degassing efficiency. However, when the ultrasonic power is increased, the cavitation bubbles can be easily formed on the basis of cavitation nucleus and grow up by coagulating with each other. Due to the melt floatation, these large bubbles can move to the surface and be removed from the melt. Hence, increasing ultrasonic power can improve the cavitation effect due to the increasing acoustic intensity.

However, it should be noted that the absorbing and escaping of hydrogen occur simultaneously on the surface of the melt, which are the two reversible processes. When the content of hydrogen in the melt is low, the external gas enters the melt by ultrasonic stirring. Therefore, when the ultrasonic power is $45 \mathrm{~W}$ and $75 \mathrm{~W}$, the degassing efficiency increases with ultrasonic treatment time. While, under the condition of $120 \mathrm{~W}$ and $150 \mathrm{~W}$ ultrasonic power treatment, the degassing efficiency decreases slightly when the ultrasonic treatment time is too long.

\subsection{Effect of ultrasonic treatment temperature on degassing efficiency}

Figure 3 shows the effect of temperature on the degassing efficiency of the 2024 aluminum alloy melt when the ultrasonic power is $150 \mathrm{~W}$. The ultrasonic treatment temperatures are $1,003 \mathrm{~K}, 983 \mathrm{~K}$ and $953 \mathrm{~K}$, respectively. It can be seen that the degassing efficiency increases with the increasing temperature. The maximum degassing efficiency increases from $32.8 \%$ to $52.5 \%$ when the treatment temperature increases from $953 \mathrm{~K}$ to $1,003 \mathrm{~K}$, which indicates a remarkable enhancement of the degassing efficiency with increasing temperature.

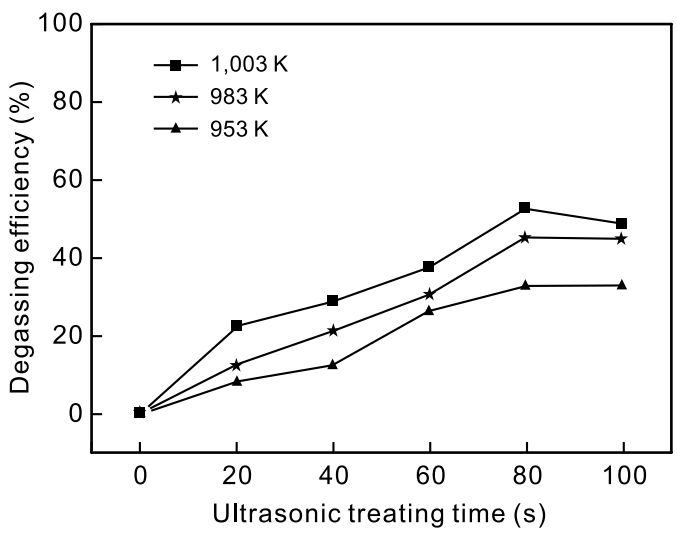

Fig. 3: Relationship between degassing efficiency and ultrasonic duration at different temperatures

The increase of degassing efficiency with temperature is related to the decrease of melt viscosity. Generally, the viscosity is higher when the temperature of the melt is lower. When the viscosity of the melt is high, the pulsating cavitation bubbles would be severely hindered by dendrites. As a consequence, it is difficult for the bubbles to coagulate or float towards the melt surface. Moreover, the critical value of cavitation depends on the viscosity of the melt. The relationship between the critical bubble radius and acoustic pressure can be expressed as the following equation ${ }^{[18]}$ :

$$
R_{0}^{3}+\frac{2 \sigma}{p_{0}} R_{0}^{2}-\frac{32 \sigma^{3}}{27 p_{0}\left(p_{0}-p_{\mathrm{c}}\right)^{2}}=0
$$

where $R_{0}$ is the minimum bubble radius to generate cavitation under a certain acoustic pressure, $\sigma$ is the surface tension of the melt, $p_{0}$ is the acoustic pressure amplitude and $p_{\mathrm{c}}$ is the static pressure. In the above equation, $\sigma$ and $p_{\mathrm{c}}$ can be considered as constant. The relationship between acoustic pressure and acoustic intensity, $I(t)$, can be given as the following equation:

$$
I(t)=\frac{p(t)^{2}}{\rho c}
$$

where $p(t)$ is the instantaneous acoustic pressure, $\rho$ is the density of aluminum melt and $c$ is the sound velocity in melt. In the above equation, the acoustic pressure is proportional to the square root of the acoustic intensity, so increasing acoustic pressure increases the acoustic intensity.

Therefore, the acoustic intensity value is higher when the radii of the bubbles are small, and it is difficult to form the cavitation when the critical value of bubble radius is large.

\subsection{Effect of ultrasonic resonance and non- resonance on hydrogen content and tensile properties of 2024 alloy}

The ultrasonic generator is adjusted to resonance before each experiment, and it can be regarded as resonant when the panel of tuning indicator is changed from 0 to 0.4 . Figures 4 and 5 show the hydrogen content and tensile properties of the 2024

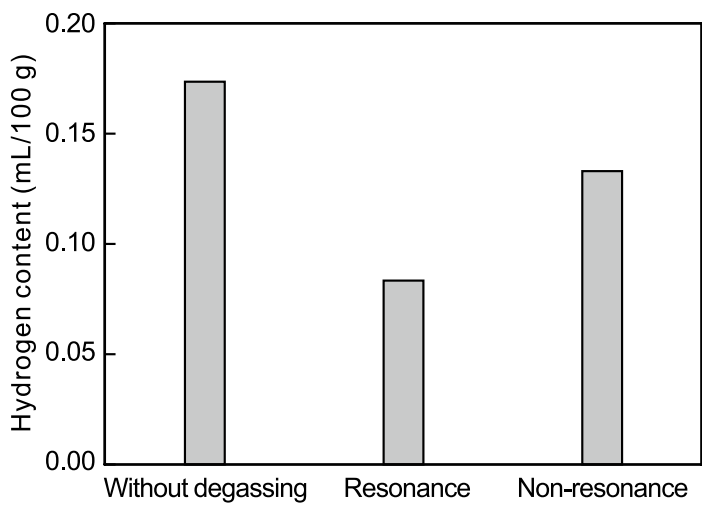

Fig. 4: Hydrogen contents of alloys under different ultrasonic treatment conditions

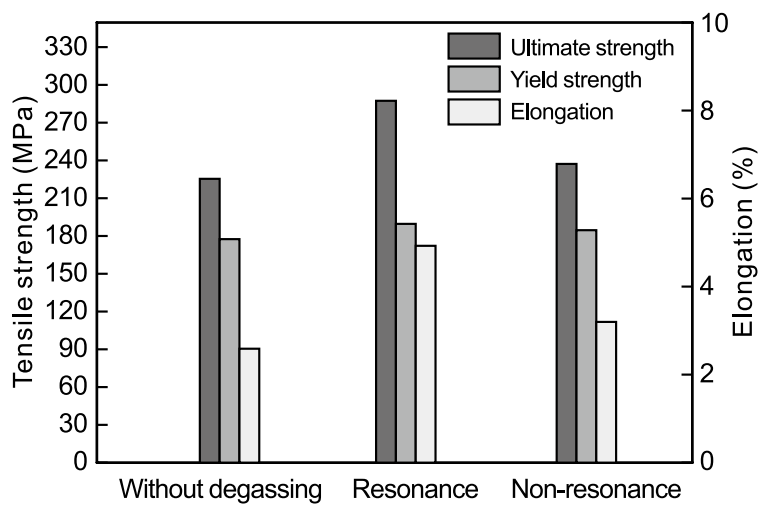

Fig. 5: Tensile properties of alloys under different ultrasonic treatment conditions 
aluminum alloy with different degassing processes (without degassing, with resonance and non-resonance under ultrasonic power of $150 \mathrm{~W}$ for $100 \mathrm{~s}$ at $1,003 \mathrm{~K}$ ).

It can be seen that the hydrogen content is lower, and the tensile properties are higher under the ultrasonic resonant condition than under non-resonant condition. So, the degassing effect under the resonant condition is better.

According to the calculations by Meidani et al. ${ }^{[19]}$, cavitation bubbles always diffuse from expansion to compression in a pulsating manner. During the expansion stage, the cavitation bubbles grow up slowly and gas content gradually increases. The gas content in the melt increases due to the gas diffusion from bubble wall to cavitation bubbles. In contrast, the cavitation bubbles grow up quickly and their surface area gradually decreases during the compression stage. So, the gas content decreases when it turns from the expansion stage to the compression stage. The described process is called the "area" effect ${ }^{[19]}$. The thickness of a liquid diffusion layer around the wall of the cavitation bubbles has an effect on the gas movement. When the cavitation bubbles are compressed, the thickness of the diffusion layer increases. At the same time, the gas concentration decreases in this layer and the gradient of gas concentration in the cavitation bubbles decreases. The gradient of gas concentration is the driving force of gas transfer, so the moving rate of gas also decreases. When the cavitation bubbles expand, the thickness of the diffusion layer decreases, the gas concentration in this layer increases, and the gradient of the gas concentration increases, and then accelerates the moving rate of gas from the melt entering into the cavitation bubbles. The described process is called the "shell" effect ${ }^{[19]}$. When the ultrasonic vibration is resonant, pulsating diffusion movements by the continuous expansion and compression of cavitation bubbles are active. Therefore, the "area" and "shell" effects of the resonant conditions are more obvious than under nonresonant conditions, leading to an efficient degassing result.

\subsection{Effects of degassing treatment conditions on hydrogen content and tensile properties of 2024 aluminum alloy}

Figure 6 shows the relationships between hydrogen content and ultrasonic treatment time with and without $1 \mathrm{wt} . \% \mathrm{C}_{2} \mathrm{Cl}_{6}$ degasser for the 2024 alloy under the condition of $150 \mathrm{~W}$ ultrasonic power and $1,003 \mathrm{~K}$ treatment temperature. When the $\mathrm{C}_{2} \mathrm{Cl}_{6}$ degasser is added, the hydrogen content of the melt decreases from $0.174 \mathrm{~mL} / 100 \mathrm{~g}$ to $0.108 \mathrm{~mL} / 100 \mathrm{~g}$, and further decreases to $0.082 \mathrm{~mL} / 100 \mathrm{~g}$ after $40 \mathrm{~s}$ ultrasonic treatment. The hydrogen content of $0.082 \mathrm{~mL} / 100 \mathrm{~g}$ is lower than the minimum value of industrial aluminum alloy melt $(0.1 \mathrm{~mL} / 100 \mathrm{~g})$. When the ultrasonic treatment time is extended to longer than $40 \mathrm{~s}$, the hydrogen content slightly increases.

Aluminum melt usually contains excessive hydrogen, and most of it is dissolved in the melt and adsorbed by inclusions. High-intensity ultrasonic treatment causes cavitation when the alternating sound pressure is negative ${ }^{[20]}$. When the frequencies of cavitation bubbles and the ultrasound are in resonance, the

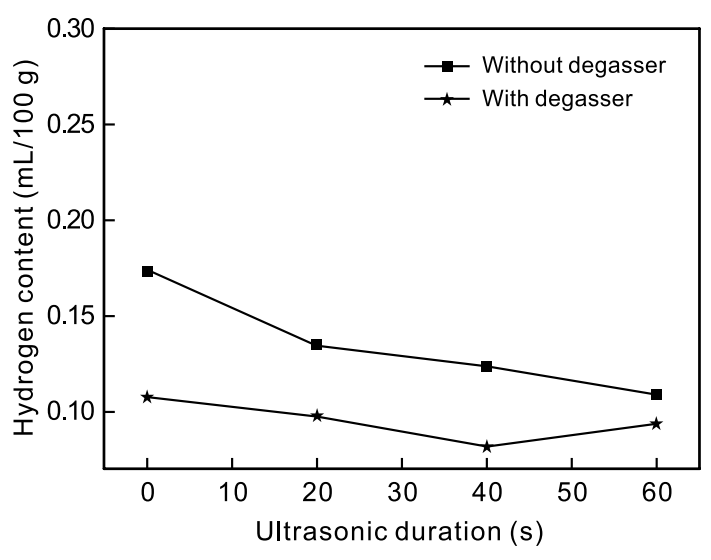

Fig. 6: Relationships between hydrogen content and ultrasonic treatment time

cavitation bubbles obviously grow. The hydrogen atoms in the melt migrate to the gas-liquid interface of the bubbles by convection and diffusion, and then change from solution to adsorption. The hydrogen atoms adsorbed in the gas-liquid interface mutually coagulate and form hydrogen molecules, which finally diffused into cavitation bubbles and the bubbles grew to big ones. In this way, the hydrogen atoms are removed from the melt. Otherwise, tiny bubbles are moved by acoustic streaming, which has great chances to coagulate. Subsequently, the bubbles float into the surface of the melt. When degasser is added in the melt, the hydrogen content sharply decreases to less than $0.1 \mathrm{~mL} / 100 \mathrm{~g}$ in a short-time ultrasonic treatment. In contrast, without degasser, the content of residual hydrogen in the melt is higher. A longer duration of treatment is needed to achieve the same hydrogen content as the one with degasser.

It is reported that the porosities in the ingots are due to the formation of bifilms in the liquid metal. Divandari et al. ${ }^{[21,22]}$ indicates that there is a layer of compact oxide films on the melt surface. When the metal melt is poured stably, these oxide films have limited effects on the quality of ingots but prevent oxidization of the melt. However, there is turbulence when the melt is poured. It causes the oxide films on the melt surface to fold collapse and finally enter the interior of the metal melt. During this process, air is entrained in the melt and forms bubbles, which is the phenomenon of bubbles entrainment.

Firstly, the bifilms are very thin, usually a few nanometers thickness, thus, oxide films will be broken up by the ultrasonic cavitation during the compression and expansion stages in the vibration. The hydrogen atoms in the melt enter the bifilms, then are wrapped and continually diffused or separated into bifilms, resulting in the increase of oxide films volume. Otherwise, these bifilms continually expand and absorb hydrogen in the melt by streaming, and when the pressure in these bifilms reaches a certain level, these bifilms will burst and escape from the melt surface. Secondly, those oxide films containing less gas continually impact and bond with each other by long time stirring of acoustic streaming, which also can remove the gas from the melt. Therefore, the bond of oxide films has substantially reduced hydrogen content and the possibility 
of porosities formation at last. It is reported that the local temperature and pressure caused by cavitation effect are nearly $10^{4} \mathrm{~K}$ and $10^{3} \mathrm{MPa}$, respectively ${ }^{[22]}$. Therefore, the fragments of the oxide film are the result of ultrasonic cavitation.

Figure shows the tensile properties of the 2024 alloy under different degassing conditions when the ultrasonic power is $150 \mathrm{~W}$ for $40 \mathrm{~s}$ and the treated temperature is $1,003 \mathrm{~K}$. As shown in Fig. 7, the tensile strength and elongation are increased from $226 \mathrm{MPa}$ and $2.6 \%$ to $290 \mathrm{MPa}$ and 5\%, improved by $28.3 \%$ and $92.3 \%$, respectively, with $1 \mathrm{wt} . \% \mathrm{C}_{2} \mathrm{Cl}_{6}$ and $40 \mathrm{~s}$ ultrasonic degassing treatment. However, the yield strength was only slightly improved by $6.7 \%$.

\subsection{Effects of different degassing processes on microstructure and porosity of 2024 alloy}

Figure 8 shows the microstructures of the 2024 aluminum alloy under different degassing conditions when the ultrasonic power is $150 \mathrm{~W}$ for $40 \mathrm{~s}$ and the treated temperature is $1,003 \mathrm{~K}$. It can be seen that some equiaxed grains appear in the solidification microstructure of the ingots, and these four ingots have similar microstructures. The melt needs to be held for $10 \mathrm{~min}$ in order to give the gas enough time to escape from the melt after treating with ultrasound, which greatly weakens the refining effect of ultrasonic treatment.
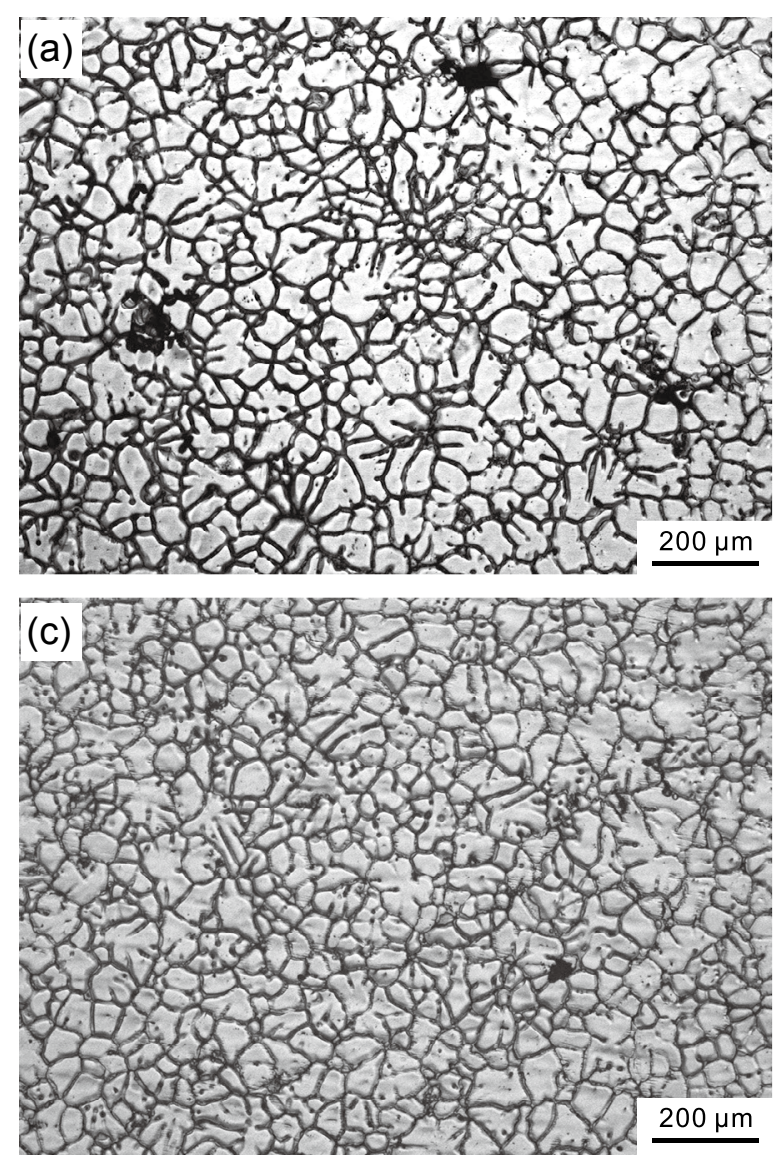

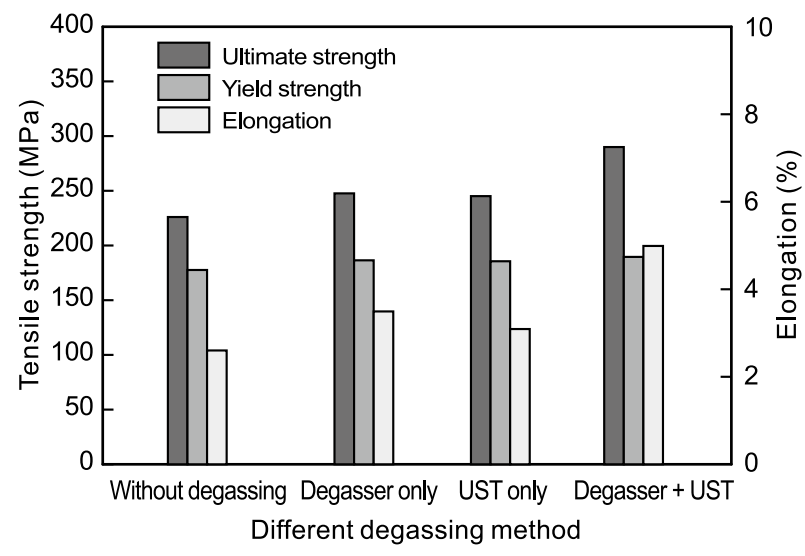

Fig. 7: Tensile properties of 2024 alloy treated under different degassing conditions

The morphologies of the porosities in 2024 aluminum alloy under different degassing conditions when the ultrasonic treatment is $150 \mathrm{~W}$ for $40 \mathrm{~s}$ and treated temperature is $1,003 \mathrm{~K}$ are shown in Fig. 9. It can be found that many porosities exist in the centre of the ingot, and the sizes of these porosities are in the range of $5 \mu \mathrm{m}$ to $150 \mu \mathrm{m}$ without degassing treatment. The sizes of porosities are decreased and the porosities are also more welldistributed with degassing treatment. It should be noted that few porosities are observed in the center of ingot when the alloy is treated with both degasser and ultrasonic treatment (hydrogen
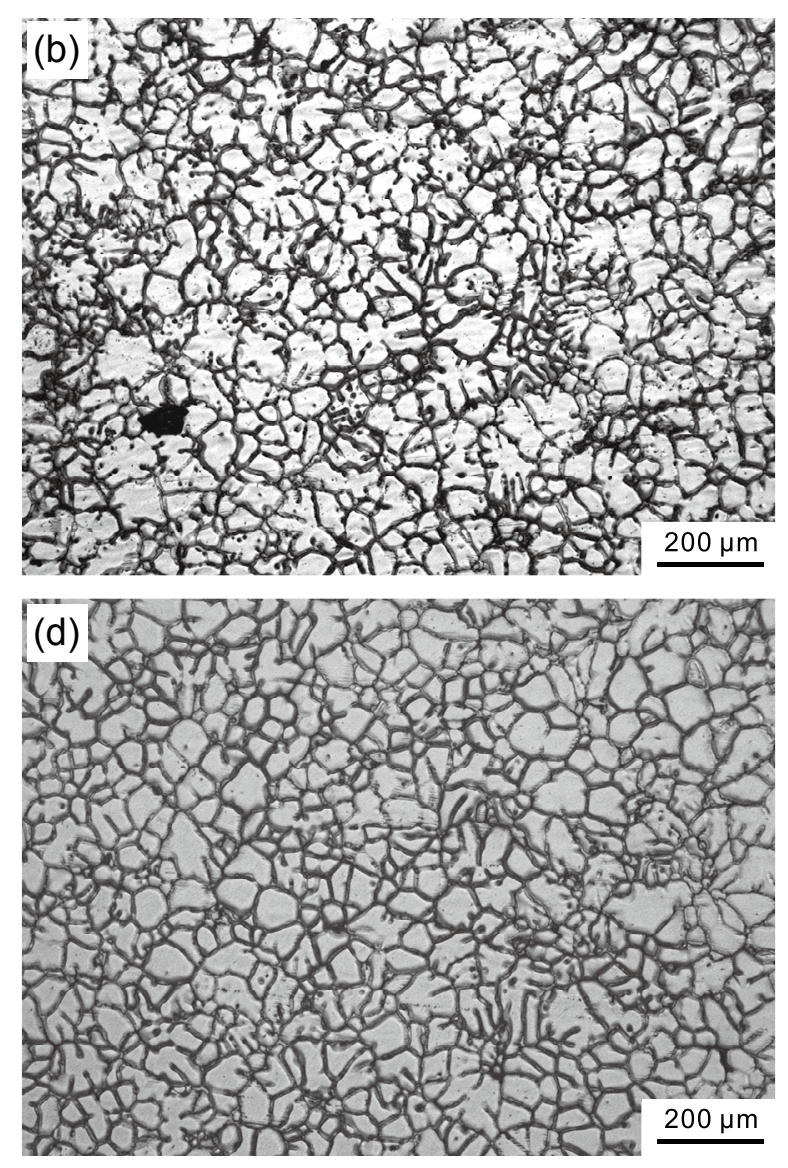

Fig. 8: Microstructures of 2024 aluminum alloy under different degassing conditions: (a) without any degassing treatment; (b) with 40 s ultrasonic treatment; (c) with $1 \% \mathrm{C}_{2} \mathrm{Cl}_{6}$ degasser; (d) with $1 \% \mathrm{C}_{2} \mathrm{Cl}_{6}$ degasser and $40 \mathrm{~s}$ ultrasonic treatment 

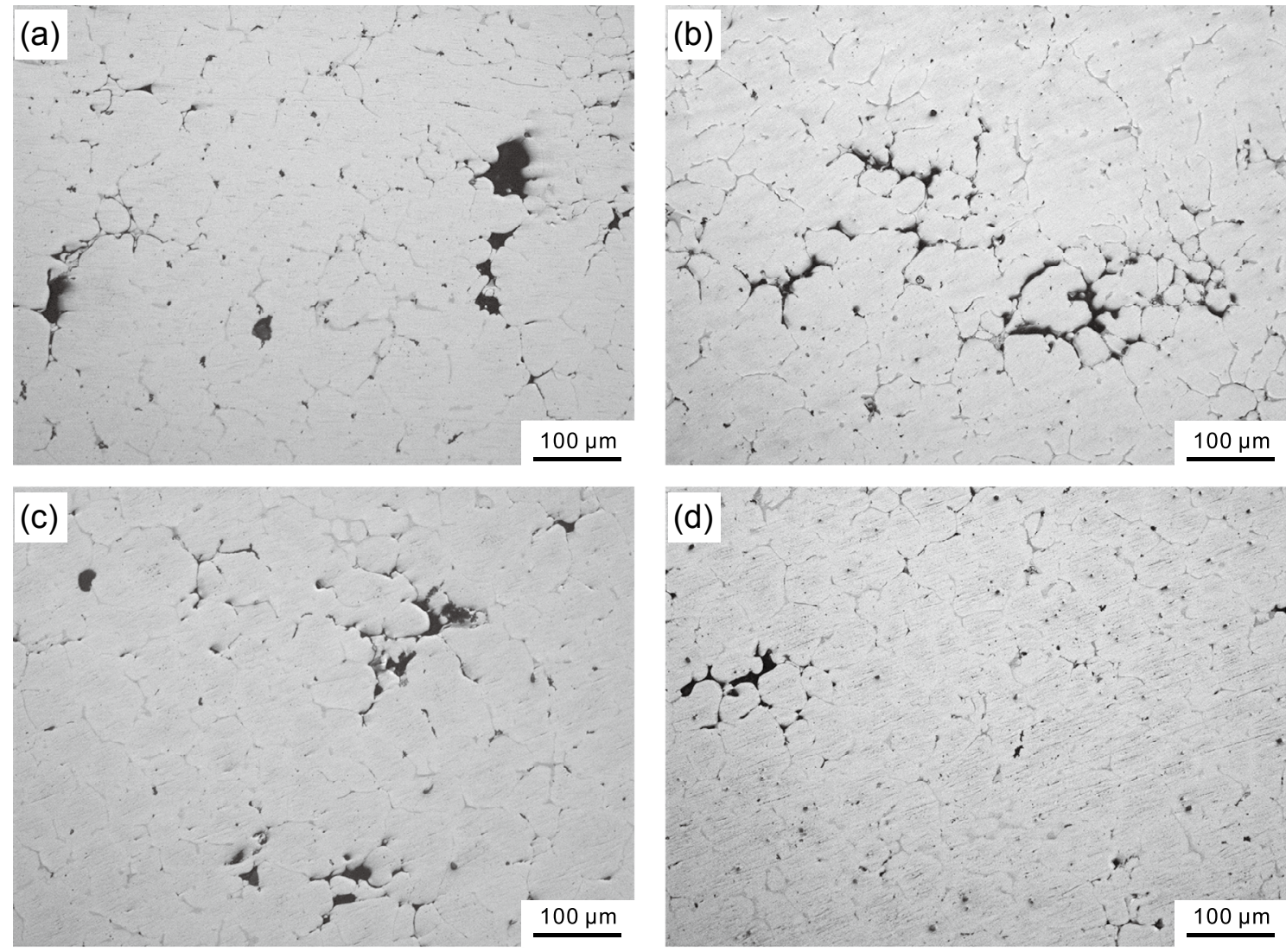

Fig. 9: Morphologies of porosities in 2024 aluminum alloy under different degassing conditions: (a) without any degassing treatment; (b) with $40 \mathrm{~s}$ ultrasonic treatment; (c) with $1 \mathrm{wt} . \% \mathrm{C}_{2} \mathrm{Cl}_{6}$ degasser; (d) with $1 \%$ $\mathrm{C}_{2} \mathrm{Cl}_{6}$ degasser and $40 \mathrm{~s}$ ultrasonic treatment

content is $0.082 \mathrm{~mL} / 100 \mathrm{~g}$ ), as shown in Fig. $9(\mathrm{~d})$. The ImageJ software was used to calculate the area of porosities in the ingots, and the results are shown in Table 3 . It can be seen that the lower the hydrogen content, the fewer the porosities. The area of porosities decreases from $1.32 \%$ to $0.27 \%$ when the alloy is treated with both degasser and ultrasonic.

Table 3: Hydrogen content and area of porosities under different degassing conditions

$\begin{array}{ccccc}\begin{array}{c}\text { Different degassing } \\ \text { methods }\end{array} & \begin{array}{c}\text { Without degassing } \\ \text { treatment }\end{array} & \begin{array}{c}\text { With 1wt.\% } \\ \mathrm{C}_{2} \mathrm{Cl}_{6} \text { degasser }\end{array} & \begin{array}{c}\text { With ultrasonic } \\ \text { treatment }\end{array} & \begin{array}{c}\text { With } 1 \text { wt. } \% \mathrm{C}_{2} \mathrm{Cl}_{6} \\ \text { degasser+ultrasonic } \\ \text { treatment }\end{array} \\ \begin{array}{c}\text { Hydrogen content } \\ \text { (mL/100 g) }\end{array} & 0.174 & 0.108 & 0.124 & 0.082 \\ \text { Area of porosities }(\%) & 1.32 & 0.67 & 0.77 & 0.27\end{array}$

\section{Conclusions}

(1) For the investigated 2024 aluminum alloy, the degassing effect is enhanced with increasing ultrasonic power. The sufficient duration of ultrasonic treatment can remove the gas from the melt effectively. The optimum degassing effect could be obtained under the ultrasonic resonance condition. The tensile properties of the alloy are greatly improved after the ultrasonic treatment under the resonance condition.

(2) The hydrogen content of the alloy is decreased by $52.9 \%$ with the combined use of $1 \% \mathrm{C}_{2} \mathrm{Cl}_{6}$ degasser and $40 \mathrm{~s}$ ultrasonic treatment. Meanwhile, the ultimate tensile strength and the elongation of the alloy are increased by $28.3 \%$ and $92.3 \%$, respectively. The yield strength is slightly increased by $6.7 \%$.

\section{Acknowledgements}

This research was financially supported by the National Natural Science Foundation of China (Grant No. 51901037), the China Post-doctoral Science Foundation (Grant No. 2019M661122), the Liaoning Province Doctoral Research Startup Fund Project (Grant Nos. 2019-BS-083, 2019-BS-168), and the Natural Science Foundation of Liaoning Province, China (Grant Nos. 2019-ZD-0561, 2019-ZD-0544). 


\section{References}

[1] Jian X, Meek T T, Han Q. Refinement of eutectic silicon phase of aluminum A356 alloy using high-intensity ultrasonic vibration. Script Materialia, 2006, 54(5): 893-896.

[2] Fu Y, Li J W, Song $X Y$, et al. Restraining solute segregation of $\mathrm{Al}-1 \% \mathrm{Si}$ alloy in diverse physical field. Materials Technology, 2012, 27(2): 173-175.

[3] Zhong G, Wu S S, Jiang H W, et al. Effects of ultrasonic vibration on the iron-containing intermetallic compounds of high silicon aluminum alloy with $2 \% \mathrm{Fe}$. Journal of Alloys and Compounds, 2010, 492: 482-487.

[4] Lin C, Wu S S, Zeng J B, et al. Combined effects of ultrasonic vibration and manganese on Fe-containing intermetallic compounds and mechanical properties of Al-17Si alloy with 3wt.\%Fe. China Foundry, 2013, 10(3): 148-154.

[5] Eskin G I. Influence of cavitation treatment of melts on the processes of nucleation and growth of crystals during solidification of ingots and castings from light alloys. Ultrasonics Sonochemistry, 1994, 1(1): S59-S63.

[6] Arshadi R, Cobbold R S C. A pioneer in the development of modern ultrasound: Robert William Boyle (1883-1955). Ultrasound in Medicine \& Biology, 2007, 33(1): 3-14.

[7] Campbell J. Effect of vibration during solidification. International Metals Review, 1981, 26(2): 71-104.

[8] Eskin G I. Ultrasonic treatment of light alloy melts. Amsterdam: Gordon and Breach Science Publishers, 1998.

[9] Abramov O V. High-intensity ultrasonics: Theory and industrial applications. US: Gordon and Breach Science Publishers, 1998.

[10] Xu H B, Han Q Y, Meek T T. Effects of ultrasonic vibration on degassing of aluminum alloys. Materials Science and Engineering: A, 2008, 473(1-2): 96-104.

[11] Xu H B, Meek T T, Han Q Y. Effects of ultrasonic field and vacuum on degassing of molten aluminum alloy. Materials Letters, 2007, 61(4-5): 1246-1250.
[12] Wu S S, Liu L F, Ma Q Q, et al. Degassing effect of ultrasonic vibration in molten melt and semi-solid slurry of Al-Si alloys. China Foundry, 2012, 9(3): 201-206.

[13] Wu S S, Lin C, Lü $S$ L, et al. Research progress on microstructure evolution of semi-solid aluminum alloys in ultrasonic field and their rheocasting. China Foundry, 2014, 11(4): 258-267.

[14] Lü S L, Wu S S, Dai W, et al. Preparation of semi-solid 5052 aluminum alloy slurry by indirect ultrasonic vibration. Acta Metallurgica Sinica, 2011, 47(5): 634-640.

[15] Wu S S, Lü S L, An P, et al. Microstructure and property of rheocasting aluminum-alloy made with indirect ultrasonic vibration process. Materials Letters, 2012, 73: 150-153.

[16] Li J W, Momono T, Yoshinori T, et al. Application of ultrasonic treating to degassing of metal ingots. Materials Letters, 2008, 62: 4152-4154.

[17] Li J W, Momono T, Fu Y. Effect of ultrasonic power on density and refinement in aluminum ingot. Foundry, 2007, 56(2): 152155. (In Chinese)

[18] Jia Z, Zhang Z Q, Le Q C, et al. Effects of ultrasonic melt treatment on degassing of AZ91 magnesium alloy. Transactions of Materials and Heat Treatment, 2012, 33(9): 38-42. (In Chinese)

[19] Meidani A R N, Hasan M. A study of hydrogen bubble growth during ultrasonic degassing of Al-Cu alloy melts. Journal of Materials Processing Technology, 2004, 147(3): 311-320.

[20] Shih T S, Huang L W, Chen Y J. Relative porosity in aluminium and in aluminium alloys. International Journal of Cast Metals Research, 2005, 18(5): 301-308.

[21] Divandari M, Campbell J. Oxide film characteristics of Al-7Si$\mathrm{Mg}$ alloy in dynamic conditions in casting. International Journal of Cast Metals Research, 2004, 17(3): 182-187.

[22] Li J W, Fu Y, Momono T. Method of fast, effective ultrasonic degassing by forced cooling. Materials Research Innovations, 2010, 14(3): 210-215. 